\title{
Anemia in Elderly Sudanese Lung Cancer Patients Treated with Chemotherapy
}

\author{
Fathelrahman Mahdi Hassan ${ }^{*}$ and Eman A. Weeda
}

\author{
College of Medical Laboratory Science, Sudan University of Science and Technology, Khartoum, Sudan
}

\begin{abstract}
Background: Cancer among Sudanese citizens has been rapidly rising since 1999 till this year and at least $80 \%$ of all patients undergo chemotherapy will develop anemia as a complication of these drugs.

Aim: To publish the Sudanese patients Hemodynamic observations during various regimen of Chemotherapy in lung cancer.

Settings and Design: This prospective observational study was conducted in the major specialized medical Radiation and Isotope Center Khartoum (RICK).

Materials and Methods: Eighty patients diagnosed of having lung cancer admitted from June 2008 to September 2009. Patients enrolled in the study were required to be $\geq 60$ years old and to have a confirmed diagnosis of lung cancer, for which they were undergoing concomitantly radio - chemotherapy.

Statistical Analysis: Analysis of data obtained by independent sample test (t-test) was performed for equality of these mean probability value.

Results: Prior treatment pre cycle I; $56.2 \%$ of patients were normal, $38.8 \%$ with mild anemia and $5.0 \%$ were had a moderate anemia. Post cycle I treatment; the normal were declined to only $9.0 \%$ and mild anemia were the highest percentage $55 \%$ followed by $28.5 \%$ for moderate anemia and $7.5 \%$ showed severe anemia. Post cycle II about $27.5 \%$ of patient showed normal hemoglobin while the majority of them $72.5 \%$ had moderate anemia.

Conclusion: A correlation of hemoglobin values after completion of therapy to overall treatment was found as a decline in range of (1 to $2 \mathrm{~g} / \mathrm{dl})$. Anemia has been demonstrated to be a predictive indicator of response to chemo radiotherapy in lung tumors.
\end{abstract}

Keywords: Cancer, lung cancer, therapy, anemia.

\section{INTRODUCTION}

Among the common age-related cancers non-small-cell lung cancer (NSCLC) must be considered a disease of older adults: the median age of newly diagnosed lung cancer patients in developed countries is approximately 68 years, and as many as $40 \%$ of patients may be older than 70 years at diagnosis [1, 14]. One of the major issues in the management of NSCLC in elderly patients is the high prevalence of co morbidity that may affect the function, the functional reserve, the quality of life, the life expectancy and the tolerance of treatment by older individuals $[2,3,14]$.

Anemia is a common finding in cancer patients and its prevalence increases after 65 years $[4,14]$. Anemia has a negative impact on the majority of organs but in an elderly cancer population the consequences can be even more invalidating due to its contribution to the 'fragility syndrome' [5]. Anemia and fatigue might precipitate functional dependence in the elderly considering that higher mobility difficulties have been reported in women aged $\geq 70$

*Address correspondence to this author at the College of Medical Laboratory Science, Sudan University of Science and Technology, Khartoum, Sudan; Tel: +249 183 773074; Fax: +249 183 773074;

E-mail: fathmaga@yahoo.com years with lower $\mathrm{Hb}$ level $[6,14]$. Furthermore, anemia causes energy imbalance and emotional distress (fatigue) [7, 14]. A direct correlation between hemoglobin levels and cognition was established by Pickett et al. [8] and they reported that increasing the hematocrit of chronic dialysis patients above $33 \%-36 \%$ with blood transfusions improved attention span, learning ability and memory [8]. With the aim of systematizing all these data, using variables, we have investigated in this prospective study whether any association exists between hematological parameters levels to evaluate anemia in elderly lung cancer patient post cycle I and II treated with chemotherapy regimens, which may improve the knowledge base in determining which patients with lung cancer may benefit from active cancer treatment and who may benefit from clinical oncologic and geriatric co-management.

\section{SUBJECTS AND METHODS}

\section{Patients Selection}

This prospective observational study was conducted in the Khartoum Isotope center, Khartoum, Sudan, between June 2008 to September 2009. 80 patients enrolled in the study were above 60 years old and to have a confirmed diagnosis of lung cancer, for which they were undergoing concomitantly radio - chemotherapy. Table 1 shows patients' 
characteristics and cancer specific treatments. All patients were evaluated before the initiation of radio chemotherapy (baseline) and before cycle I (after 21 days) for quality of life, mental capacity, functional status, and depression and co morbidities. The consent was obtained from patients after being informed with details objectives of the study. $2.5 \mathrm{ml}$ of whole blood samples were collected from each patient (three times) in EDTA container and proceed for determination of complete blood count before(pre cycle I) and after (post cycle I and post cycle II) therapy regimens.

Table 1. Patients Characteristics

\begin{tabular}{|l|r|}
\hline Age (Years) (mean \pm SD) & $66.4 \pm 3.2$ \\
\hline Sex M/F & $68(85) / 12(15)$ \\
\hline Tumor Type & $5(6.2 \%)$ \\
\hline Lung unspecified & $3(3.8 \%)$ \\
\hline SCLC & $72(90.0 \%)$ \\
\hline NSCLC & \\
\hline Stage & $10(12.5 \%)$ \\
\hline IIIA & $26(32.5 \%)$ \\
\hline IIIB & $44(55.0 \%)$ \\
\hline IV & \\
\hline Line of Treatment & $80(100.0 \%)$ \\
\hline Post cycle I & $80(100.0 \%)$ \\
\hline Post cycle II & \\
\hline
\end{tabular}

\section{Statistical Methods}

Data were summarized using frequencies and proportions or mean \pm standard deviation (SD) and $95 \%$ confidence interval (CI), as appropriate. To account for multiple testing, only $P$ values $<0.01$ were considered as statistically significant and those $<0.002$ as highly significant (equivalent to an overall type-I error of about 0.05 for each of the six indexes and for all indexes, respectively, under the highly conservative assumption of total independence between measures).

\section{RESULTS}

Eighty lung cancer patients (lung unspecific, small-cell lung cancer (SCLC) and non-small-cell lung cancer (NSCLC)) aged $\geq 60$ with mean of 66.4 years ( 68 male and 12 female) were enrolled in the study. Table 1 summarizes the patients' characteristics. Five (6.2\%) patients were diagnosed of having lung cancer unspecific, 3 (3.8\%) of them were SCLC and $72(90.0 \%)$ of patients were type NSCLC lung cancer at different stages (stage; IIIA, IIIB and IV).

The anemia was evaluated according to the hemoglobin level setting as $11 \mathrm{~g} / \mathrm{dl}$ was normal level. After the baseline evaluation pre-cycle I, patients were visited before therapy cycle I(21 days) at least until post cycle I. the hematological parameters were measured at each of the three visits completed by all patients (pre cycle I, post cycle I and post cycle II), along with the nominal associated $\mathrm{P}$ values, have been calculated. Pretreatment (control) $\mathrm{Hb}$ level ranged from 11.0 to $9.0 \mathrm{~g} / \mathrm{dl}$. No patient had $\mathrm{Hb}<8 \mathrm{~g} / \mathrm{dl}$. During the treatment in post cycle I most patient $\mathrm{Hb}$ ranged from 9.0 $\mathrm{g} / \mathrm{dl}$ to $10.0 \mathrm{~g} / \mathrm{dl}$ and in post cycle II, all patients $\mathrm{Hb}$ ranged from $11.0 \mathrm{~g} / \mathrm{dl}$ to $10.0 \mathrm{~g} / \mathrm{dl}$. We recorded a decrease of the $\mathrm{Hb}$ level after treatment completion in most patients (Table 2).

Patients who received concomitantly radio chemotherapy were anemic depending on hemoglobin level at some point, and the proportion of anemic patients increased across therapy cycles. For patients receiving Cisplatin-based regimens, the rate of anemia increased from $55 \% \mathrm{Hb}$ level at cycle 1 to $68 \%$ at cycle 2 . For patients receiving non-Cisplatin-based regimens, the rate of anemia was also increased dependency on the based regimen which was used (Table $\mathbf{3}$ ).

Treatment schedules also expressed change related to some hematological parameters such as; total white blood cells (TWBC), hemoglobin (Hb), red blood cells count (RBCs), platelet count and absolute netrophil count (ANC) which were interpretive as mean values in post cycle I and post cycle II only because patients were tested as predictors of response early in the course of chemotherapy, but their predictive value has not been compared with that of a simple early clinical assessment. The overall hematological changes due to radio and chemotherapy regimens compared to control (Table 4).

\section{DISCUSSION}

In our elderly lung cancer patients $\mathrm{Hb}$ level was associated with the different in chemotherapy cycle depending on the type of therapy. Moreover the change in $\mathrm{Hb}$ level was associated with the change in most parameters although not significantly for others. This suggests that the treatment of anemia or maintenance of adequate $\mathrm{Hb}$ levels could be useful to preserve or improve quality of life and overall health status in elderly lung cancer patients

Table 2. Distribution of Hemoglobin Levels Among Patients with Lung Cancer

\begin{tabular}{|c|c|c|c|c|}
\hline \multicolumn{2}{|c|}{ Mean } & \multicolumn{2}{c|}{ Patients Number, $\mathbf{n}$ (The Percent of Patients that have Hb Value, \%) } \\
\hline Hb g/dL & Hb \% & Pre-Cycle I (Control) & Post-Cycle I & $7(9.00)$ \\
\hline $\mathbf{1 1 . 0 0}$ & $\mathbf{7 3 . 3 \%}$ & $45(56.20)$ & $44(55.00)$ & $22(27.50)$ \\
\hline $\mathbf{1 0 . 0 0}$ & $\mathbf{6 6 . 6 \%}$ & $31(38.80)$ & $23(28.50)$ & $58(72.5)$ \\
\hline $\mathbf{0 9 . 0 0}$ & $\mathbf{6 0 . 0} \%$ & $4(5.00)$ & $6(7.50)$ & $0(0.0)$ \\
\hline $\mathbf{0 8 . 0 0}$ & $\mathbf{5 3 . 0} \%$ & $0(0.00)$ & $80(100.0)$ & $0(0.0)$ \\
\hline Total & & $80(100.0)$ & $80(100.0)$ \\
\hline
\end{tabular}


Table 3. Hematological Parameters in Control (Pre Cycle I) and Post-Cycle I and II Chemotherapy Among Patients with Lung Cancer

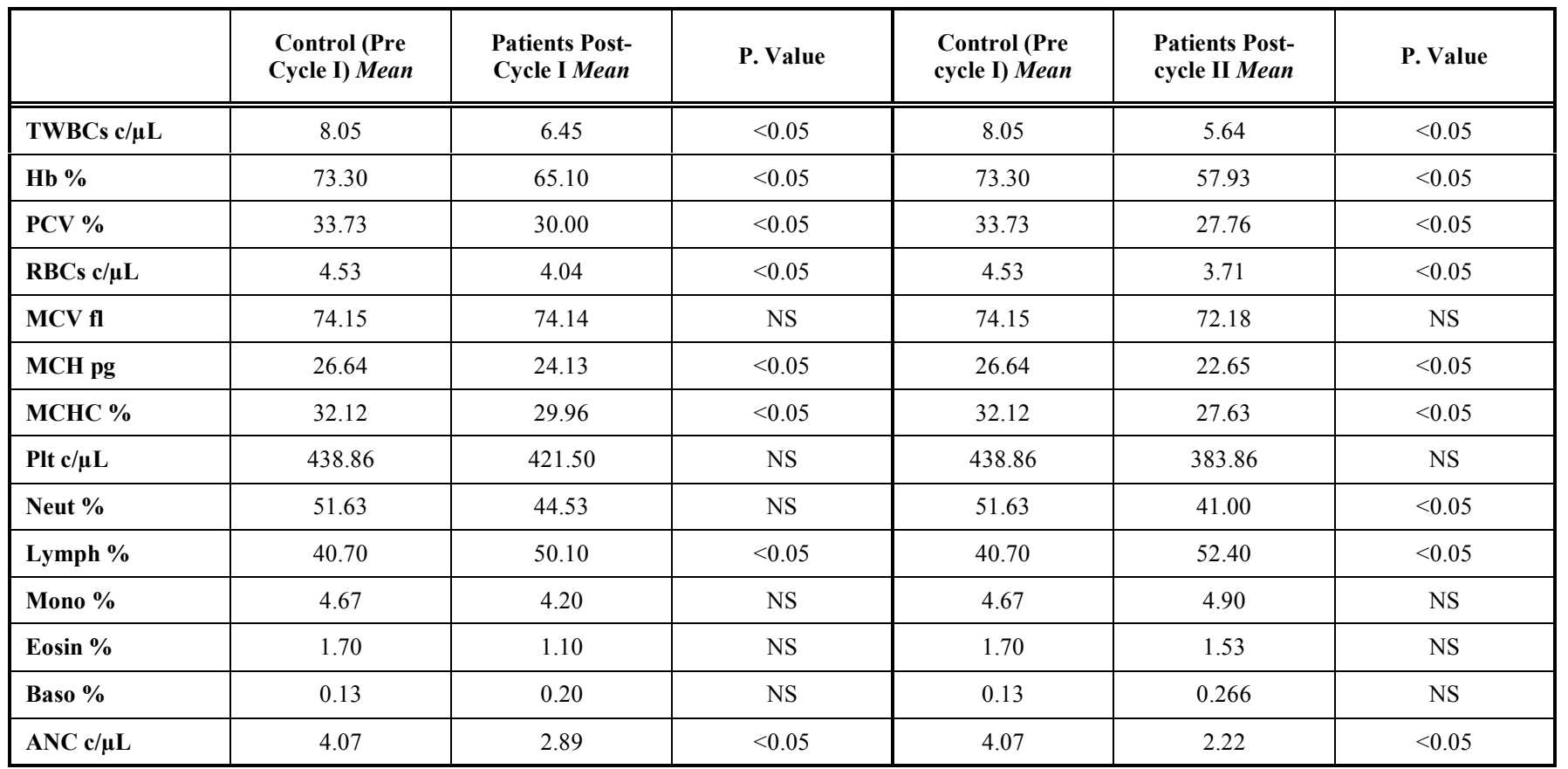

NS: Non significant.

$\mathrm{TWBC}=$ Total white Blood cell, $\mathrm{MCH}=$ Mean cell hemoglobin, $\mathrm{Hb}=$ Hemoglobin, $\mathrm{MCHC}=$ Mean cell hemoglobin, $\mathrm{PCV}=\mathrm{Packed}$ cell volume, $\mathrm{Plt}=\mathrm{Platelet}$ count, $\mathrm{RBC}=$ Red blood cell, Neut $=$ Neutrophil, $\mathrm{MCV}=$ Mean cell volume, $\mathrm{Lymph}=$ Lymphocyte, Esino $=$ Eosinophil, Mono $=$ Monocyte, Baso $=$ Basophil, ANC $=$ Absolute Neutrophil count.

Table 4. Chemotherapy Schedule and Some Hematological Changes in Post-Cycle I and II

\begin{tabular}{|c|c|c|c|c|c|}
\hline Regimen & \multicolumn{5}{|c|}{ Mean (P. Value) } \\
\hline Pre-cycle I & 8.05 & 73.30 & 4.53 & 438.86 & 4.07 \\
\hline \multicolumn{6}{|l|}{ Post-Cycle I } \\
\hline $\mathbf{A}$ & $5.97(<0.05)$ & 72.67(NS) & $4.15(\mathrm{NS})$ & $464.67(\mathrm{NS})$ & $2.49(<0.05)$ \\
\hline $\mathbf{C}$ & $4.70(<0.05)$ & $68.00(<0.05)$ & $4.20(\mathrm{NS})$ & $609.00(<0.05)$ & $7.66(<0.05)$ \\
\hline D & $6.50(<0.05)$ & $61.50(<0.05)$ & $4.10(\mathrm{NS})$ & $430.00(\mathrm{NS})$ & $2.60(<0.05)$ \\
\hline \multicolumn{6}{|l|}{ Post-Cycle II } \\
\hline B & $6.52(<0.05)$ & $65.67(0.050)$ & $3.84(<0.05)$ & 427.00(NS) & $2.65(<0.05)$ \\
\hline
\end{tabular}

NS: Non significant.

Treatment:

A: Docetaxel - Platinum $\left(35 \mathrm{mg} / \mathrm{m}^{2} /\right.$ weekly)

B: Etoposide - Cisplatin ( $20 \mathrm{mg} / \mathrm{m}^{2} /$ weekly).

C: Vinorelbine - Cisplatin $\left(25 \mathrm{mg} / \mathrm{m}^{2} /\right.$ weekly).

D: Radiotherapy (2000 CGy/weekly).

undergoing chemotherapy. These results are one of the clinical evidences of guidelines (ASCO-ASH, NCCN, EORTC) that recommend the treatment of mild anemia level $(\mathrm{Hb} 10-12 \mathrm{~g} / \mathrm{dl})$ in an elderly population with co morbidities [9. 14].
Anemia may adversely influence the management of older cancer patients receiving chemotherapy with or without radiotherapy by limiting the dose intensity and the dose density of the treatment and thus preventing adequate cancer control. In addition, anemia may increase the cost of treating cancer by causing prolonged disability and more [10]. Our prospective survey analyzed correlations between anemia 
induced chemotherapy and hematological parameters. A European study of anemia and cancer reports that anemia is common in lung cancer patients and often untreated.

In interpreting the results of this study, however, one should be aware that other factors, such as patient's performance status, chemotherapy regimen and response to chemotherapy, may have interacted with the $\mathrm{Hb}$ level and the other variables examined. Investigating the role of these factors in an observational study would require a larger patient population and complex analysis models. Therefore, notwithstanding these promising results, further larger controlled clinical studies are needed to confirm the role of therapy and to establish more clearly when anemia correction becomes absolutely necessary. In conclusion, the correlation of Anemia and outcomes of therapy for lung cancer, would be established prognostic and relatively improvement in survival conferred by radiation in lung cancer related to haemoglobin level to evaluation of anemia during first and second chemotherapy cycles in lung cancer patients.

Our finding was in agreement with the results from the European Cancer Anemia Survey (ECAS) [11] suggest that anemia is common in lung cancer patients and that current treatment patterns are less than optimal. Patients who were treated for anemia often did not receive anemia treatment until hemoglobin levels were relatively low. Anemia treatment is important to maintaining quality of life in patients with lung cancer. Given the high frequency of anemia in lung cancer patients and the often late initiation (or non-initiation) of anemia treatment, changes in anemia monitoring and management may be warranted. Our results seem to show that, even in lung cancer patients receiving chemo radiotherapy, anemia is able to predict clinical response to treatment. According with our findings, several studies indicated a defined role of pretreatment $\mathrm{Hb}$ value. However, most of these data come from retrospective analyses and other trials did not confirm these results. MacRae et al. [12] demonstrated that presenting $\mathrm{Hb}$, average $\mathrm{Hb}$ and minimum $\mathrm{Hb}$ level during therapy were not statistically significant predictive of survival in lung cancer patients, while declining $\mathrm{Hb}$ during chemo radiotherapy had a significant improvement. Decline changes in the TWBCs and ANC can represent a primary disorder of leukocyte production or may reflect a secondary response to the disease process or toxin [13].

\section{ACKNOWLEDGEMENTS}

I thank Dr Alkhateeb and Dr Ihsan for interviewing and study assistance. We are also grateful for the time and commitment of the study participants.

\section{REFERENCES}

[1] Bunn PA Jr, Lilenbaum R. Chemotherapy for elderly patients with advanced non-small-cell lung cancer. J Natl Cancer Inst 2003; 95: 341-3.

[2] Extermann M. Measurement and impact of comorbidity in older cancer patients. Crit Rev Oncol Hematol 2000; 35: 181-200.

[3] Balducci L, Hardy CL. Anemia of aging: a model of erythropoiesis in cancer patients. Cancer Control 1998; 5(Suppl 1): 17-21.

[4] Ania BJ, Suman VJ, Fairbanks VF, Rademacher DM, Melton LJ 3rd. Incidence of anemia in older people: an epidemiologic study in a well- defined population. J Am Geriatr Soc 1997; 45: 825-31.

[5] Ludwig H, Fritz E. Anemia in cancer patients. Semin Oncol 1998; 25: 2-6.

[6] Chaves PHM, Ashar B, Guralnik JM, Fried LP. Looking at the relationship between hemoglobin concentration and prevalent mobility difficulty in older women. Should the criteria currently used to define anemia in older people be reevaluated? J Am Geriatr Soc 2002; 50: 1257-64.

[7] Gutstein HB. The biologic basis of fatigue. Cancer 2001; 92(Suppl): 1678-83.

[8] Pickett JL, Theberge DC, Brown WS, Schweitzer SU, Nissenson AR. Normalizing hematocrit in dialysis patients improves brain function. Am J Kidney Dis 1999; 33: 1122-30.

[9] Lichtin A. The ASH/ASCO clinical guidelines on the use of erythropoietin. Best Pract Res Clin Haematol 2005; 18: 433-8.

[10] Shen JG, Cheong JH, Hyung WJ, Kim J, Choi SH, Noh SH. Pretreatment anemia is associated with poorer survival in patients with stage I and II gastric cancer. J Surg Oncol 2005; 91: 126-30.

[11] Kosmidis P, Krzakowski M, The ECAS Investigators. Anemia Profiles in Patients with Lung Cancer: What Have We Learned From the European Cancer Anaemia Survey (ECAS)? Lung Cancer 2005; 50: 401-12.

[12] Dubray B, Mosseri V, Brunin F, et al. Anemia is associated with lower local-regional control and survival after radiation therapy for head and neck cancer: a prospective study. Radiology 1996; 201: 553-8.

[13] Coates TD, Baehner RL. Leukocytosis and leukopenia. In: Hoffman R, Benz EJ, Shattil SJ, Furie B, Cohen HJ, Eds. Hematology basic principles and practice. $1^{\text {st }}$ ed. NewYork: Churchill Living Stone 1991; p. 552.

[14] Mancuso A, Migliorino M, De Santis S, Saponiero A, De Marinis A. Correlation between anemia and functional/cognitive capacity in elderly lung cancer patients treated with chemotherapy. Ann Oncol 2006; 17(1): 146-50. 